\title{
Climate Transitions: Forcing and Feedback Mechanisms of Glacial- Interglacial and Recent Climate Change
}

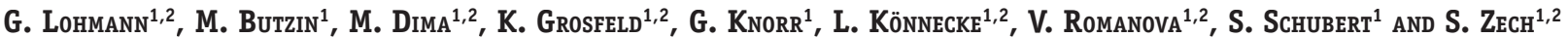 \\ 'Bremen University, Center for Marine Environmental Sciences, P.O. 330440, 28334 Bremen, Germany; gerrit.lohmann@dkrz.de. \\ ${ }^{2}$ Alfred Wegener Institute for Polar and Marine Research, P.O. 120161, 27515 Bremerhaven, Germany.
}

It is of vital importance to understand whether increasing human population and industrialization have already caused, or have the potential to induce significant changes in Earth's climate. Unfortunately, direct temperature records that enable the detection of climate changes on a global scale are too short and they already fall within the period of strong human impact on natural conditions. Information regarding the pre-anthropogenic state of the system can be obtained either from proxies that record past climate and environmental conditions, or by simulating the climate system with numerical models under appropriate external forcing. The paleoclimate record provides an excellent test of these models as it reveals climate variations that have occurred in the past. Computer simulations and conceptual models contribute to a system-analytical understanding of the dynamics in the climate system. The project covers climate variability and transitions for recent climate changes, the Holocene, deglaciation, and the last glacial cycle (Fig. 1, in Lohmann and Sirocko, this issue). Linkages exist with nearly all DEKLIM-Paleo projects, special collaborations are with CorClim, RESPIC, GHOST, Oxygen Isotopes, and EEM.

\section{Climate Shift in the 1970's}

We investigate the signature of North Atlantic multidecadal variability based on statistical analysis of observed and proxy data, as well as general circulation model experiments (Lohmann et al., 2004; Grosfeld et al., 2004). The signature of North Atlantic multidecadal SST variability has a monopolar structure, whereas the sea level pressure variability is found to be similar to that of the North Atlantic Oscillation (NAO). The signature of multidecadal North Atlantic variability is also well recorded in independent proxy time

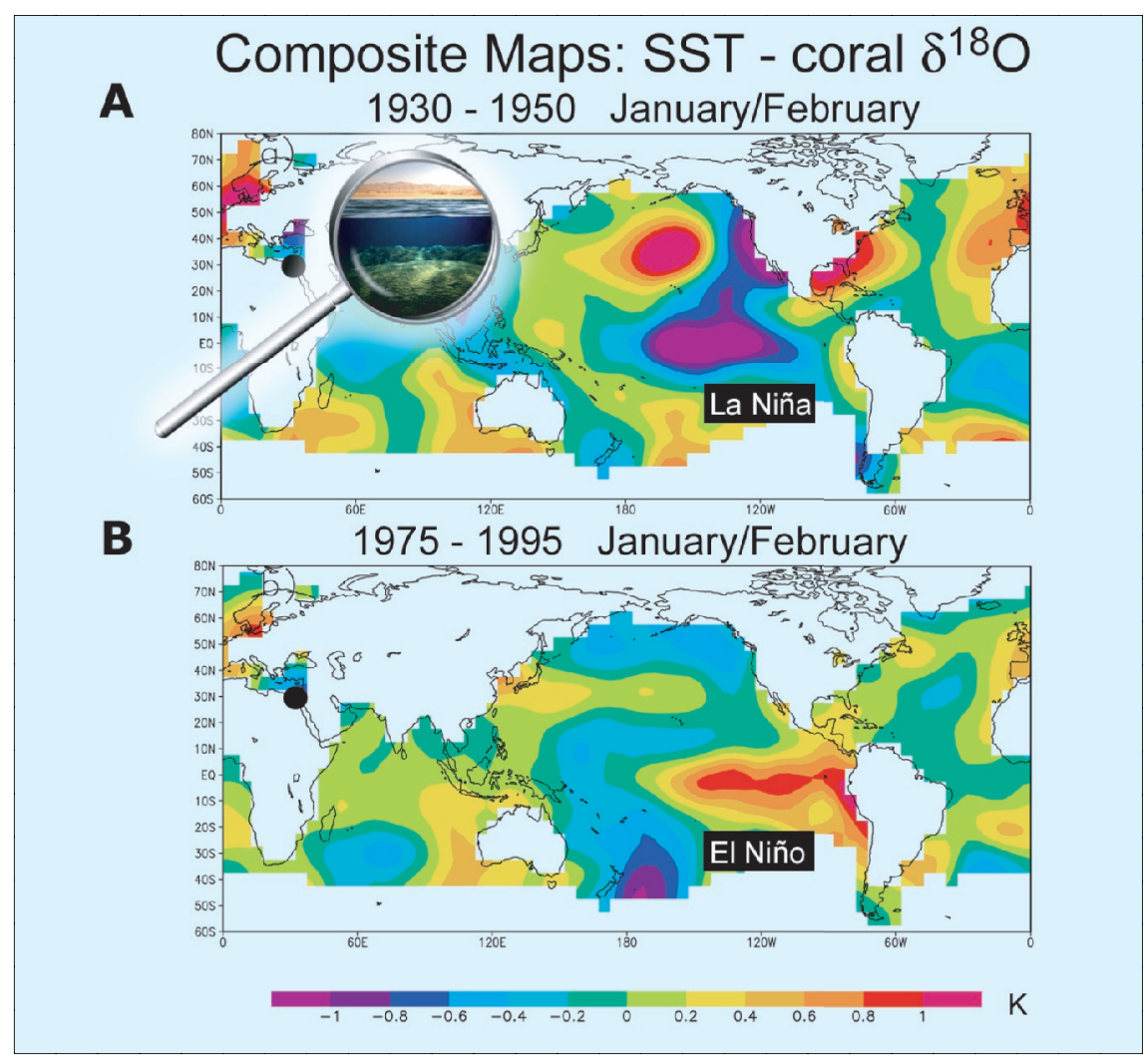

Fig. 1: Composite analysis of oxygen isotope in the Red Sea coral with SSTS (Kaplan et al., 1998). (a) Positive anomalies of the coral record from the mid-1930's to late 1960's are associated with a strong Pacific-North Atlantic teleconnection accompanied by a weak Aleutian Low, a more zonal flow at mid-latitudes, and La Niña conditions in the tropical Pacific. (b) In contrast, positive anomalies of oxygen isotopes in the Red Sea coral after the 1970's are related to El Niño conditions and weaker Pan-Pacific-Atlantic circulation regimes.

series. We find that global teleconnections are modulated on interdecadal time scales (Rimbu et al., 2003), which provides a limitation in the prediction and reconstruction of remote climate phenomena such as the El Niño-Southern Oscillation (ENSO) impact over Europe (Fig. 1).

\section{Deglaciation}

Analyses of ice-core and ocean-sediment records have shown that for the last two deglaciations, changes in temperatures over Antarctica and the tropics precede changes in Greenland ice volume (Petit et al., 1999; Henderson and Slowey, 2000; Lea et al., 2000). We present a mechanism for deglaciation whereby an increase in tropical SSTs, as observed at the end of glacial periods, can impact the surface temperature over the Laurentide
Ice Sheet via an atmospheric bridge (Rodgers et al., 2003). This study is based on atmospheric general circulation experiments where changes in tropical SST can drive changes in air temperature over modern-day Canada (Fig. 2a).

Another teleconnection is linked to a Southern Ocean warming and associated sea ice retreat onto the Atlantic thermohaline circulation (THC) (Knorr and Lohmann, 2003): a gradual warming in the Southern Ocean induces an abrupt resumption of the THC by increased mass transport via the warm and cold water route of the global oceanic conveyor belt circulation. Potential thresholds and interactions of the THC with the hydrological cycle are investigated for glacial and present day conditions (Prange et al., 2002; Lohmann, 2003; Prange et al., 2004; 
A

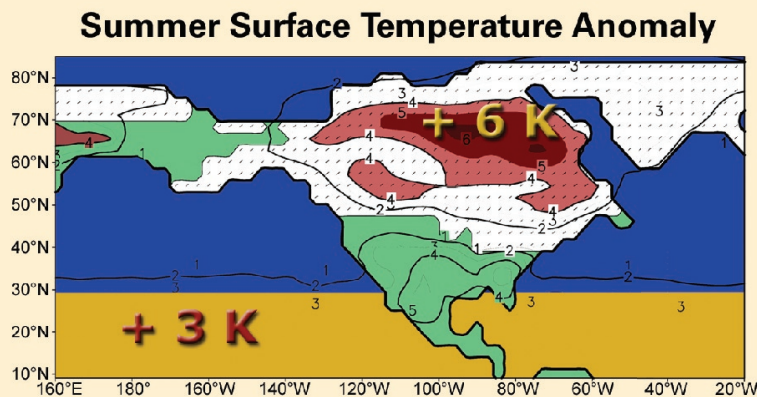

B

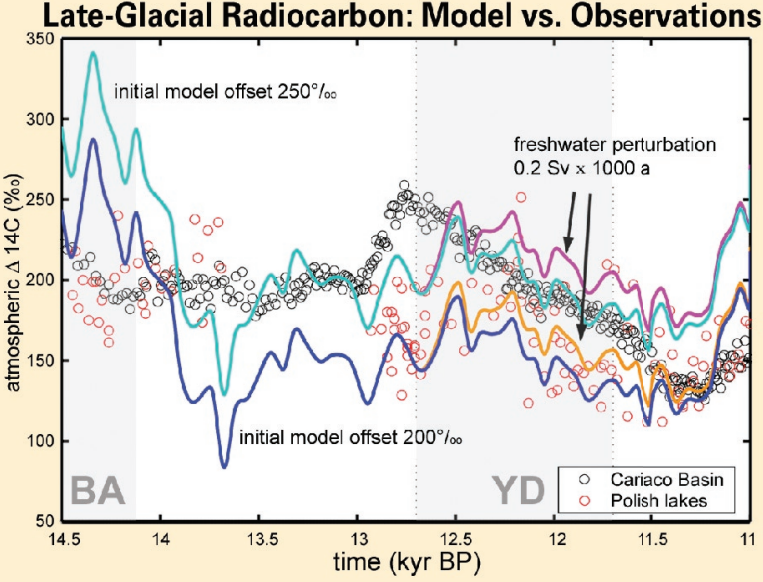

Fig. 2: Deglaciation. (a) The role of the tropics in the melting and reforming of the Laurentide Ice Sheet on glacial timescales is analyzed by an atmospheric general circulation model. It is found that warming of tropical SSTS from glacial boundary conditions causes a large increase in summer temperatures centered over the ice-sheet-forming regions of Canada. (b) Temporal evolution of the atmospheric radiocarbon concentration $\delta^{14} \mathrm{C}$ during the Late Glacial period. Circles denote values inferred from sediment data (data sources: Cariaco Basin: Hughen et al., 2000; Polish lakes: Goslar et al., 2000). The curves are model results, obtained with an ocean general circulation model coupled to an atmospheric reservoir (Buzin et al., 2004), which is also subject to changes in cosmogenic ${ }^{14} \mathrm{C}$ production las estimated by Marchal et al., 2001). The simulations started at 17 kyr BP using different initial values, as there is consider able uncertainty regarding the atmospheric radiocarbon concentration at that time (e.g., see Goslar, 2001). If an initial value of $250 \%$ is assumed, the model agrees over longer periods with the Cariaco Basin derived $\delta^{14} \mathrm{C}$ history; starting with $200 \%$ yields better agreement with the varved lake-sediment record from Poland. Both simulations do not reproduce the steep increase of atmospheric radiocarbon at the beginning of the Younger Dryas cold period (YD), even in the case where deepwater formation in the North Atlantic is shut down by a meltwater perturbation. Conversely, for the Bølling/Allerød warm phase (BA) the model suggests elevated atmospheric values that do not show up in the geological records.

Romanova et al., 2004). The results may help to assess the effect of iceberg invasions and meltwater events, suggesting that the THC is prone to instability during a degla- ciation phase. However, modeling results indicate several mismatches between modeled and reconstructed ${ }^{14} \mathrm{C}$ concentration (Fig. 2b). One is possibly linked to an abrupt onset of vigorous deepwater formation during the Bølling warm period.

\section{Conclusions and Outlook}

Teleconnections and their role in long-term climate variability are investigated using numerical models of the Earth's system. To reconstruct climate change over thousands of years, it is necessary to use the evidence provided by sediments, ice cores, pollen data, fossil and isotope records (e.g. Rühlemann et al., 2004; Felis et al., 2004). Analyzing paleoclimatic records and models in tandem enables the evaluation of climate transitions and the analysis of forcing and feedback mechanisms of glacial-interglacial and future climate changes.

\section{REFERENCES}

Felis, T., Lohmann, G., Kuhnert, H., Lorenz, S., Scholz, D. Pätzold, J., Al-Rousan, S.A. and Al-Moghrabi, S.M., 2004: Increased seasonality in Middle East temperatures during the last interglacial period. Nature 429, 164-168.

Knorr, G., and Lohmann, G., 2003: Resumption of the Atlantic conveyor circulation via Southern Ocean warming during deglaciation. Nature 424, 532-536. Lohmann, G., Rimbu, N. and Dima, M., 2004: Climate signature of solar irradiance variations: Analysis of long-term instrumental, historical, and proxy data. International. Journal of Climatology 24 (8) 1045-1056. doi: 10.1002/joc.1054.

Rimbu, N., Lohmann, G., Felis, T., and Pätzold, J., 2003: Shift in ENSO teleconnections recorded by a Red Sea coral. J. Climate 16, 1414-1422.

Rodgers, K., Lohmann, G., Lorenz, S., Schneider, R., and Henderson, G., 2003: A tropical mechanism for Northern Hemisphere deglaciation. Geochem., Geophys., Geosyst. 4, 1046, doi: 10.1029/ 2003GC0000508

For full references please consult: www.pages-igbp.org/products/newsletters/ref2004_2.html

\section{Tree-Rings, Isotopes, Climate and Environment: TRICE}

\section{G. Helle ${ }^{1}$ and 0. Panferov}

${ }^{1}$ Forschungszentrum Jülich GmbH, ICG-V: Sedimentary Systems, 52425 Jülich, Germany; g.helle@fz-juelich.de ${ }^{2}$ Georg-August-University Göttingen, Inst. of Bioclimatology, Büsgenweg 2, 37077 Göttingen, Germany

Tree-rings from temperature-limited sites provide low frequency climate proxy data for the last 1000 years (e.g. Esper et al. 2002). However, it is still unclear to what extent and by what processes climatic signals are exactly mirrored in the tree-ring archive. An improved knowledge of tree-ring response to current climate forc- ing is, thus, imperative to advance predictions in climate change.

The TRICE project (www.triceproject.de) uses stable carbon and oxygen isotopes as a) indicators for processes underlying tree growth and b) climate proxies. Thus, TRICE investigates the impact of changing environmental quantities on tree growth.
Mechanistic modeling and novel transfer functions, combining tree-ring proxies (ring width, wood density, isotopes) help to develop measures for tracing Holocene climate variability from the tree-ring archive.

Trees are located at the junction of the water cycle, which controls the distribution of pre- 